\title{
Technology Enabled Language Learning Using CALL and MALL
}

\author{
P Sathya, Monica Prems and Sahaya Drishiya Raj \\ Department of English, Holy Cross College (Autonomous), Nagercoil, India
}

\section{ABSTRACT}

The paper titled "Technology Enabled Language Teaching using CALL and MALL" aims at exploring the effectiveness of language teaching using CALL and MALL wherein the traditional methods of teaching were not inculcated. It also highlights the teaching of English language during the pandemic. This paper gives a detailed account of the different ICT tools and computer and mobile applications that are used by the teachers of English predominantly during the pandemic. These applications enable the learners to think critically and interact meaningfully. The learners are engaged in meaningful interaction with the advent of technology. It also critiques on the pros and cons of technology enhanced language learning using Computer Assisted Language Learning (CALL) and Mobile Assisted Language Learning (MALL). It further adds the effective use of these techniques in classroom and the impact in the field of education irrespective of time and place.

KEY WORDS: COMPUTER ASSISTED LANGUAGE LEARNING, MOBILE ASSISTED LANGUAGE LEARNING, LANGUAGE LEARNING, COMPUTER AND MOBILE APPLICATION, ICT.

\section{INTRODUCTION}

In the past few decades Information and Communication Technology (ICT) has provided society with new hope for better future. ICT refers to technology that provides access to information through telecommunications. ICT is similar to Information Technology, but it focuses communication technology that includes internet, mobile phone, wireless network, broadcasting technology (radio and television) and other communication media. People can communicate with one other across the globe through technology.

ICT plays a major role in the enhancement of English language skills and also in the field of ELT. The learners can enhance their language skills with the help of various tools such as CALL, MALL, CAI, E-magazines, etc. These modern technological tools provide information not only in learning a language, but also in other fields such as science, games, entertainment, etc. The usage of computers, internet and online tutorials has made the learners more involved towards English language learning. ICT is a boon not only to the learners but

Biosc Biotech Res Comm P-ISSN: 0974-6455 E-ISSN: 2321-4007

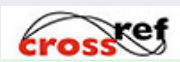

Identifiers and Pagination

Year: 2021 Vol: 14 No (8) Special Issue

Pages: 06-11

This is an open access article under Creative

Commons License Attribn 4.0 Intl (CC-BY).

DOI: $h t t p: / / d x$.doi.org/10.21786/bbrc/14.8.2 it has also enhanced the knowledge repertoire of the teachers in using the ICT tools by educating the upcoming generations in a fruitful way. Thus ICT is very essential in this present era to improve our knowledge in every arena.

Computer Assisted Language Learning (CALL): Computer Assisted Language Learning (CALL) is a method in which computer and computer based tools are used as an aid to present and also in the assessment of material which is to be learned, using a substantial interactive element in teaching and learning a second or a foreign language. CALL can be shortly defined as learning a language using computer technology. Computer Assisted Instruction (CAI) was first used in 1950s but initially they were not used in language teaching. The use of computers began as early as 1950s and it was first used in the University of Illinois. There are two typologies of CALL, namely, Warschaue and Bax. Warschauer's typology of history of CALL is based on three phases namely Structural CALL, Communicative CALL and Integrative CALL. On the other hand, Bax proposed the history of CALL in terms of approaches namely Restricted CALL, Open CALL and Integrated CALL. Warschauer's typology is divided in chronological order so his typology is more prominent.

Structural Call: Structural CALL originated in the 1950s and is based on behaviourism, wherein the computers take up the role of tutors to the learners by providing training and materials to the learners. The most widely used was PLATO (Programmed Logic for Automated Teaching
Article Information

Received: $05^{\text {th }} \mathrm{Apr} 2021$

ccepted after revision: $14^{\text {th }}$ June 2021 
Operation), introduced in the university of Illinois. The PLATO system includes drills on vocabulary, grammar and translation.

Communicative Call: The second phase is Communicative CALL which was developed during 1970s as a reaction to the behavioural theory. As the name indicates, the importance was given to communication skills. This include pace reading, asking directions to the readers, conversation, critical thinking and language games and the computer remains as a tutor. It enhances the listening and reading skills of the learners. It also enhances the vocabulary and grammatical skills of the learners.

Integrative Call: Integrative CALL was developed in 1990s wherein the importance was given all the basic skills, namely, listening, speaking, reading and writing. Multimedia computers and World Wide Web were the basics of Integrative CALL. Network based technology allows the learners to access the learning material whenever and wherever they want. They were also able to use the computer regularly and it also paved a way for the learners to interact among them without any barrier. This phase gives opportunity to learners not only in interacting with the tutor but also to the fellow learners.

The three phases of CALL did not overcome the other. They just co-exist with one another. Over the decades, CALL has improved a lot. At first it was used only by few but now it became the mainstream in language learning. This is mainly because of the advancement of technology. In this era, technology has become a part of daily life which allows learners to use it regularly. Learners were also able to adapt to technology easily and it paved a way to connect with other people across the world. CALL has evolved to represent various divisions namely, Computer Mediated Communication, Blended learning, Virtual worlds, etc. due to the diversity of digital technology. There are also many sub division such as CALL for ESP (English for Specific Purpose), CALL for EAP (English for Academic Purpose) and so on. Thus CALL is not a single subject now; it has become a quickly evolving tool in language learning.

Mobile Assisted Language Learning (MALL): In the recent years, technology has been widely developed and it has made a great impact in all the fields, especially in the field of education. Educational technology has been an interesting field that makes learners, teachers and technology work together in a productive way. It comprises several fields including language theory, computer based training, online learning and also m-learning, where mobile technologies are used. Mobile phones are one of the most commonly used gadgets in our day to day lives. People of all age groups, including children use mobile phones for various purposes. Initially mobile phones were only used for communication. Later, various features were introduced such as SMS, camera, playing games, listening to songs, taking videos, browsing and so on. The development of mobile phones is very massive and bigger needs for using it in the language learning process.

Mobile Assisted Language Learning (MALL) is language learning that is assisted or enhanced through the use of a handheld mobile device. It is a subset of both Mobile learning (m-learning) and Computer Assisted Language Learning (CALL). M-learning or mobile leaning is leaning across multiple contexts, through social and content interactions, using personal electronic devices. MALL has evolved to support learners language learning with the increased use of mobile technologies such as mobile phones, MP3 and MP4 players, PDA's and devices such as the iPad. Mobile learning environment might be face to-face, distance or online. Mobile learning is very comfortable and creates a better ambiance for all the learners within their own space and time. The history of MALL began with a research in 1980s by Twarog and Pereszlenyi Pinter. They used telephones to provide distance language learners with feedback and assistance. Later it was used in various institutions, organizations and Universities over the world in shaping the educational level in a creative manner.

Review of Literature: Ouseph (2013) in his article titled Integrating EFL CALL,'E-B-M Learning': New Trends in ELT states that CALL plays a vital role in language learning context of both synchronous and asynchronous modes. EFL podcasting and Blended learning has transformed the face to face medium to e-learning medium. These methods provide multiple modalities which are preferred by large number of learners. The integration of EFL, CALL and E-B-M learning helps both learners and teachers to make use of various learning tools.

Madhavi (2014) in her article titled Computer Assisted Language Learning (CALL): Developing Writing Skills using Study Skill Success Software discusses the development of writing skills through CALL. She also uses Study Skill Success Software as a reference. Writing skills involve audience, information, tone, language and length. The use of multimedia technology, computers, and online resources has become a necessary thing in one's career in this 21st century. Word processor provides Spell check, Grammar check, Thesaurus, dictionary, synonym and antonym thus enabling the learners to enhance their writing skill. Verma (2011) in her paper titled Multimedia \& ICT in English Language Education points out the positive and negative aspects of CALL (Computer Assisted Language Learning). In this article, the author presents the Transmission Control Protocol and Internet Protocol which allow computers anywhere in the world to get access to CALL.

Kumar (2014) in his article titled Critical Assessment of ELT through Self Instructional Material through CALL \& Smart English Laboratory - Features and Specifications points out the use of Computer Assisted Language Learning (CALL). The author focuses on students' attitude towards CALL approach on teaching oral skills and the results have proven that CALL helps the learners 
to enhance their vocabulary for thinking, writing and speaking.

Lakshmi (2012) in her article titled Technology Enabled Learning in Classroom Situation: A Small Scale Survey states the advantages of using Computer Assisted Language Learning (CALL). She also presents a survey conducted on 120 B.Tech students to show us the use of CALL. Ahamad, Rogers, Sussex and Corbett (qtd. in Lakshmi) states that "CALL arouse from the combination of two separate factors: educational need and technological needs with both pedagogy and technology together as the focus of CALL research, the final systems implemented more accurately meet the language learning educational needs by providing a plethora of language learning activities." Some of the activities in CALL are gap - filling exercises, comprehension passages, simulations, vocabulary games, etc. to improve one's communication skill.

Rahnavard and Heidar (2017) in their article titled The Impact of Computer- Assisted Language Learning (CALL) / Web- Based Instruction on Improving EFL Learners' Pronunciation Ability points out the impact of CALL on improving the pronunciation ability in EFL learners. A survey was conducted to check the pronunciation skills of learners and the results were satisfactory. Miangah and Nezarat (2012) in their article titled Mobile Assisted Language Learning explain the ways in which a mobile phone can be used as a tool in learning a second language. It also further states the advantages of m-learning and the various ways in which it can help the learners improve their language skills in their own place. It states how m-learning can be effective even without the assistance of teachers. Mobile based learning has faced so many challenges but it still paves a way for language learning in all contexts of the world.

\begin{abstract}
Alemi et al (2012) in their article titled Successful Learning Of Academic Word List Via MALL: Mobile Assisted Language Learning explains how mobile learning can access learners to acquire new vocabulary than classroom learning. It gives an idea of presenting the vocabulary by accessing SMS Yang (2013) in his article titled Mobile Assisted Language Learning: Review of the Recent Applications of Emerging Mobile Technologies focuses on the review of analyzing how m-learning serves as a learning factor in helping both learners and teachers. It says how m-learning has drastically developed in recent times. Joshi and Shah (2015) in their article titled Mobile Assisted Language Learning (MALL) and its role in learning of English Language explains in a detailed way how MALL is easy and convenient to the second language learners and also represents the ideas of learners towards learning MALL in classrooms. The attitude and also the comprehending ability of the learners is also important in learning a language.
\end{abstract}

Sherine and Supriya (2020) in their article titled Promoting Vocabulary Learning Through MALL: A Comparative study explain how MALL can be useful and found easier and encouraging for the tertiary level learners outside their classroom. Flipped classroom along with MALL were used in the classroom and the results were found satisfactory. Materials such as Google forms, Kahoot app and online dictionary, You tube videos, word games were also used by the experimental group. The use of CALL and MALL has proven to be satisfactory in language learning. With the help of computers and mobiles, the learners have enhanced their communication skills and benefited in a larger scale. It not only provides them good learning ambience but also gives them a positive vibe to engage themselves on the whole. CALL and MALL keep them connected all over the world mentally. Recently, the use of CALL and MALL has risen in all the countries due to the pandemic. Online education has been a domain and this has made language learning using CALL and MALL more useful in these days. Thus Mobile Assisted Language Learning is all set to transform and guide the educational scenario in the present days.

Strategies And Issues In CALL And MALL: In today's education scenario, learners and teachers are battling with technology. Technology has revolutionized the way teachers teach and learners learn. Most of the people spend their time in using computers, mobiles and tablets in their homes as well as in schools and colleges. Learners find it easy to adapt to technology based learning since they are used to it but some teachers find it hard to enroll themselves in technology based teaching and learning as well.

The use of CALL and MALL has grown a lot in last decade. Many find that learning a language through CALL and MALL has its own merits than demerits. Both CALL and MALL are approaches to language teaching and learning and the best way to learn it thoroughly is in the future. A number of studies have proved that the use of CALL and MALL have affected the development of learners' language skills. Many researchers have found that only reading and listening are enhanced through CALL and MALL. Writing skills have not been as impressive since computers cannot assess this well. Using computer technology in classrooms helps the learner to develop their self-concept and it encourages student centered learning. Computers act as a tutor for language practice. It also acts as a tool for presenting, writing and guiding the learners.

\section{Merits of CALL And MALL}

The merits of using CALL and MALL are:

- They enhance the communication skills of the learners.

- The learners can learn in their own pace.

- Both CALL and MALL are learner-centered.

- They can choose their own mode of learning

- They can also learn whenever and wherever they want

- Teachers can provide study materials according to the learners' level which is not possible in the traditional method of teaching.

- The learners are relieved from stress.

- Learners, who feel less confident and prefer 
individual learning can be benefited from CALL learning.

- Both CALL and MALL provide new opportunities for informal learning unlike the traditional classrooms.

- They help the learners to think critically.

- They encourage collaborative learning.

- $\quad$ One can make use of multiple learning styles into an allotted topic as it motivates the learners.

- The teachers can adopt alternative methods of teaching using CALL and MALL.

- $\quad$ Through e-mail and chat rooms learners are able to connect with their peers across the world.

- The learners can even connect with the native speakers which would eventually help them to acquire the target language.

- Learning through computers and mobiles facilitate them by engaging in global communication with the help of these platforms.

- CALL and MALL encourage the learners to participate in classroom activities and this helps them to gain self-confidence.

- The use of CALL and MALL makes the learning process more exciting.

- CALL and MALL provide immediate feedback to the learners and it helps them to rectify their mistakes.

- CALL and MALL promote individualization, flexibility and the ability to learn outside the classroom. It encourages experimental learning.

- CALL and MALL provide various study materials from different sources and so the learners were not confined to a single source of information.

- CALL and MALL act as guide as well as a tutor to the learners.

Demerits of CALL And MALL: Though CALL was introduced in 1960s, many were not familiar with this mode of language acquisition. Only in the past decade the use of CALL has increased. Though it helps the learners in many ways it has some disadvantages which cannot be neglected.

The demerits of CALL and MALL are as follows:

- This is highly expensive and learners from poor background cannot afford to CALL and MALL.

- The educational institutions have to spend huge amount of money for language lab and softwares which also require regular updation. Most of the institutions are not ready for renewal which ultimately affects the learning process.

- Some teachers are competent enough to use technology and they refrain from using it. Though they are given training at the beginning, they do not update themselves.

- Lack of communication between the teachers and software professionals are not continuous.

- The attention span of the learners is less than seven minutes and the teachers find it difficult to get the attention of the learners.

- CALL and MALL focus more on enhancing the listening, reading and writing skills of the learners whereas speaking skill is totally neglected. Equal importance should be given to all the four skills.

- The computers cannot provide answers immediately to the doubts the learners have as teachers do. The learner should wait for the answer. The motivation level is also low in CALL and MALL and so the teacher should act as a motivator and a guide.

- The learners might get easily distracted while using CALL and MALL. Especially, while using mobiles, the learners might get distracted when they receive messages from social media and the like.

- $\quad$ Since the screen in the computers and mobiles are too small, sometimes the learners suffer from physical ailments. These are some of the negative aspect of using CALL and MALL in language learning. The teachers should be given proper training and also they should be highly resourceful. They should be competent learners to learn new technology. They should be equally motivated that of learners. The teacher should select tools that work best for them.. Though there are some merits and demerits no one can deny the fact that learning a language through CALL environment has positive effect on learners.

\section{CONCLUSION}

The use of internet has changed many things in the world. It has even changed the way we communicate and access information. Teachers have also understood that the use of technology in learning will help the learners in their future workplace environment. In the current era where everything is technology based it is important for the learners of all age groups including the teachers to be aware of these beforehand. It may be difficult for teachers and learners to upgrade themselves along with the growing technology and software. Thus ICT is highly recommended for the awareness of tools and techniques in the developing fields. Information and Communication Technology (ICT) plays a major role in all fields. Technology based learning and teaching and Technology Enhanced Language Learning (TELL) facilitates the learning process for learners. As technology helps in online learning it also became a handy tool in language learning.

Computer Assisted Language Learning (CALL) and Mobile Assisted Language Learning (MALL) are language learning softwares that make the learning process easier. Computer Assisted Language Learning (CALL) uses electronic devices or computers to give educational instruction to the learners. It can be used in all fields of education. Similarly Mobile Assisted Language Learning (MALL) uses mobile phones in teaching and learning a language. MALL is also a subset of m-learning and Computer Assisted Language Learning.

\section{REFERENCES}

Alemi, Minoo, et al. "Successful Learning of Academic Word List via MALL: Mobile Assisted Language Learning." International Education Studies, vol. 5, no. 6, 2012, pp. 99-109, Research Gate, www.researchgate. net/publication/266226487_Successful_Learning_of_ 
Academic_Word_List_via_MALL_Mobile_Assisted Language_Learning. Accessed 20 0ct. 2020.

Al-Ghawi, Hussain S. (2019). Technology Enhance Language Learning (TELL). May 2019, www.slideshare. net/Mobile/hussainalghawi/technology-enhancelanguage-learning-tell. PowerPoint Presentation.

Alsuhaibani, Zainab. "Using Computer Assisted Language Learning in Classroom: What Does Research say about Teachers' Beliefs and Practices?" www. academypublication.com/ojs/index.php/tpls/article/ view/tpls0906723728. Accessed 210ct. 2020.

Chapelle, Carol. "The Spread of computer - assisted language learning." pdfs.semanticscholar.org/545c/ ece 2 af098c842b5490d1b 1 feced54202113a.pdf . Accessed 20 0ct. 2020.

Chimney, George M. "Emerging technologies going to the MALL: mobile assisted language learning." www. researchgate.net/publication/228389166_Emerging_ technologies_going_to_the_Mall_moblie_assisted_ language_learning. Accessed 13 Oct. 2020.

Chinchole, Subodh.N. "Moblie Assisted Language Learning: Scope and Limitations in Rural and Semi Urban Indian context.' www.languagepoinindia.com/ aug2019/subodhmobileassistedlanguagelearning.pdf. Accessed 15 Oct. 2020.

Derakhshan, Ali, et al. "Computer- Assisted Language Learning (CALL): Pedagogical Pros and Cons." International Journal of English Language and Literature Studies, vol. 4, no. 3, 2015, pp. 111-20. Research gate, www.researchgate.net/publication/299381901_ Computer-Assisted_Language_Learning_call_ pedagogical_prons_cons. Accessed 18 0ct. 2020.

Joshi, Om; Shah, Scenil. "Mobile Assisted Language Learning (MALL) and It's Role in Learning of English Language." eltvoices.in/mobile-assisted-languagelearningmall-and-its-role-in-learning-of-englishlanguage-by-om-joshi-sunil-shah/ . Accessed 2 Nov. 2020.

Kumar, Praveen Chinta. "Critical Assessment of ELT through Self Instructional Material through CALL and Smart English Laboratory- Features and Specifications."

Lakshmi.N. "Technology Enabled Learning in Classroom Situation: A Small Scale Survey.” sites.google.com/ site/journaloftechnologyforelt/archive/january-2012/ technology-based-learning- . Accessed 12 0ct. 2020. Lindaman, Dana and Dan Nolan. "Moblie-Assisted Language Learning: Application Development Projects within Reach for Language Teachers.” IALLT Journal of Language Technologies, vol. 45, no. 1, 2015, pp. 1-21. Academia, www.academia.edu/13175983/ Moblie_Assisted_Language_Learning_Application_ Development_Projects_within_Reach_for_Language_ Teachets . Accessed 20 0ct. 2020.

"Mobile- assisted language learning." En.m.wikipedia. org/wiki/mobile-assisted-language-learning. Accessed 10 0ct. 2020.
Madhavi, K.V. "Computer Assisted Language Learning (CALL): Developing writing skills using Study Skills Success Software." sites.google.com/ sitejournaloftechnologyforelt/archive/vol-no-2-1/1. Accessed 24 0ct. 2020.

Miangah, Tayebeh Mosavi. and Amin Nezarat. "MoblieAssisted Language Learning." International Journal of Distributed and Parallel Systems (IJDPS), vol. 3, no. 1, Jan. 2012, pp. 309-19. ResearchGhate, www. researchgate.net/publication/271600581_Moblie_ Assisted_Language_Learning . Accessed 11 Oct. 2020. Mirani, Javed Iqbal, et al. "A Review of ComputerAssisted Language Learning (CALL): Development, Challenges, and Future Impact." Education and Linguistics Research, vol. 5, no. 1, 2019, pp. 37-45. Macrothink Institute, www.macrothink.org/journal/ index.php/elr/article/download/14515/11453. Accessed 19 Nov. 2020.

Ouseph, Nalkara Shaju. "Integrating EFL CALL, 'E-B-M Learning”: New Trends in ELT.” sites.google.com/site/ journaloftechnologyforelt/archive/january2013-no-4/5integrating-efl-call-e--b-m-learning-new-trends-in-elt. Accessed 22 0ct 2020.

Pirasteh, Pravin. "The Effectiveness of Computerassisted Language Learning (CALL) on Learning Grammar by Iranian EFL Learners.” www.sciencedirect. com/science/article/pii/51877042814026524. Accessed 29 0ct. 2020.

Prasad, Shesha. N. Various Approaches and Methods of Teaching English. www.slideshare.net/NSheshaprasad/ approaches-and-mrthods-of-teaching-english. PowerPoint Presentation.

Rahnavard, Fereshteh; Davood Mashhadi Heider. "The Impact of Computer-Assisted Language Learning (CALL)/ Web-Based Instruction on Improving EFL Learners' Pronunciation Ability." International Journal of Research in English Education, vol. 2, no. 1, Jan. 2017, pp. 49-57. ResearchGhate. uww researchgate.net/publication/314238331_The_Impact_ of_Computer_Assisted_Language_Learning_CALL_ Web-Based_Instruction_on_Improving_EFL_Learners'_ Pronunciation_Ability

Sherine, Supriya M.J. "Promoting Vocabulary Learning Through MALL: A Comparative Study." www. researchgate.net/publication/344467269_PROMOTING_ VOCABULARY_LEARNING_THROUGH_MALL_A_ COMPARATIVE_STUDY . Accessed 29 Nov. 2020.

sites.google.com/site/journaloftechnologyforelt/archive/ vol-4-no-1-jan-mar-2014/2. Accessed 24 Oct. 2020. Stevie .D, "Teachers on CALL: What Educators Must Know About Computer Assisted Language Learning." FluentU. www.fluent.com/blog/educator/what-iscomputer-assisted-language-learning/. Accessed 23 Oct. 2020.

Turc , Lorena. "Mobile- Assisted Language Learning (MALL).” Rate.org.ro/blog2.php/1/mobile-assistedlanguage-learning-mall. Accessed 15 Nov. 2020. 
Valarmathi, K.E. “Mobile Assisted Language- LearningJournal of Technology for ELT.” Sites.google.com/ site/journaloftechnologyforelt/archive/april/2011/ mobileassistedlanguagelearning. Accessed 10 Nov. 2020.

Verghese, Paul c. "Teaching English as a Second Language.” Sterling Publishers, 2016.

Verma, Anupama. "Multimedia and ICT in English Language Education.” Sites.google.com/ site/journaloftechnologyforelt/archive/april2011/ multimediainenglisheducation. Accessed 22 0ct. 2020.
Vincent, Elizabeth; Mauren Han. "Strategies employed by users of a Japanese computer assisted language learning (CALL) program.” Pdfs.semanticscholar. org/5461/e478a47b658ca49f7852fbb3617e78670c34. pdf. Accessed 11 Nov. 2020.

Yang, Jaeseok. "Moblie Assisted Language Learning: Review of the Recent Applications of Emerging Mobile Technologies."

www.researchgate.net/287427601_Mobile_Assisted_ Language_Learning_Review_of_the_Recent_ Applications_of_Emerging_Mobile_Technologies . Accessed 12 Nov. 2020 